\title{
Symposium
}

\section{Law and Neuroscience}

\author{
Owen D. Jones, ${ }^{1,2}$ René Marois, ${ }^{3}$ Martha J. Farah, ${ }^{4}$ and Henry T. Greely ${ }^{5}$ \\ ${ }^{1}$ Vanderbilt Law School and Department of Biological Sciences, Vanderbilt University, Nashville, Tennessee 37203, ${ }^{2}$ MacArthur Foundation Research \\ Network on Law and Neuroscience, Nashville, Tennessee 37203, ${ }^{3}$ Department of Psychology, Vanderbilt University, Nashville, Tennessee 37203, \\ ${ }^{4}$ Department of Psychology, Center for Neuroscience \& Society, University of Pennsylvania, Philadelphia, Pennsylvania 19104, and ${ }^{5}$ Stanford Law School, \\ Center for Law and the Biosciences, Stanford University, Stanford, California 94305
}

\section{Introduction}

Law and neuroscience seem strange bedfellows. But the engagement of law with neuroscientific evidence was inevitable. For one thing, the effectiveness of legal systems in regulating behavior and meting out justice often depends on weighing evidence about how and why a person behaved as he or she did. And these are things that neuroscience can sometimes illuminate. For another, lawyers are ethically bound to champion their clients' interests. So they remain alert for new, relevant, or potentially persuasive information, such as neuroscience may at times offer, that could help to explain or contextualize behavior of their clients.

In light of this, and in the wake of remarkable growth in and visibility of neuroscientific research, a distinct field of Law \& Neuroscience (sometimes called "neurolaw") has emerged in barely a decade (Garland, 2004; Zeki and Goodenough, 2006; Gazzaniga, 2008; Freeman and Goodenough, 2009; Mackintosh, 2011; Spranger, 2011; Davis, 2012; Jones and Shen, 2012; Morse and Roskies, 2013; Jones et al., 2013a). Whether this engagement is ultimately more for better or for worse (there will be both) will depend in large measure on the effectiveness of transdisciplinary partnerships between neuroscientists and legal scholars. How can they best help the legal system to understand both the promise and the perils of using neuroscientific evidence in legal proceedings? And how can they help legal decision-makers draw only legally and scientifically sound inferences about the relationships between particular neuroscientific evidence and particular behaviors?

In this article, we highlight some efforts to establish and expand such partnerships. We identify some of the key reasons why neuroscience may be useful to law, providing examples along the way. In doing so, we hope to further stimulate interdisciplinary communication and collaborative research in this area. This article is not meant to be a comprehensive review but rather is intended to highlight a Symposium at the 2013 Society for Neu-

\footnotetext{
Received July 31, 2013; revised Sept. 27, 2013; accepted Sept. 28, 2013

Author contributions: 0.D.J., R.M., M.J.F., and H.T.G. wrote the paper.

This work was supported in part by the John D. and Catherine T. MacArthur Foundation (grant to Vanderbilt University). Its contents reflect the views of the authors and do not necessarily represent the official views of either the John D. and Catherine T. MacArthur Foundation or The MacArthur Foundation Research Network on Law and Neuroscience.

The authors declare no competing financial interests.

Correspondence should be addressed to Owen D. Jones, Vanderbilt Law School and Department of Biological Sciences, Vanderbilt University, 131 21st Avenue, South, Nashville, TN 37203. E-mail: owen.jones@vanderbilt.edu. DOI:10.1523/JNEUROSCI.3254-13.2013

Copyright $\odot 2013$ the authors $\quad 0270-6474 / 13 / 3317624-07 \$ 15.00 / 0$
}

roscience Annual Meeting. (For a more thorough review, readers are referred to Jones and Shen, 2012).

\section{Lobes and robes: the intersection of neuroscience and law}

Clear statistics are hard to find, but many indicators suggest that courts are increasingly encountering offers of neuroscientific evidence. Why? Among other reasons, many people in the legal system hope that insights from neuroscience can help to answer some of the hard and perennial questions law routinely faces. These include questions, such as follows: Is this person responsible for his behavior? What was this person's mental state at the time of the act? How much capacity did this person have to act differently? What are the effects of addiction, adolescence, or advanced age on one's capacity to control behavior? How competent is this person? What does this person remember? How accurate is this person's memory? What are the effects of emotion on memory, behavior, and motivation? Is this person telling the truth? How much pain is this person in? How badly injured is this person's brain?

Of course, the relevance of neuroscience to law depends intimately on the specific legal issue and context. And neuroscientific evidence is but one kind of evidence, to be weighed alongside other kinds. But, speaking quite generally, neuroscientific evidence might aid law in at least seven (sometimes overlapping) ways (Jones, 2013):

1. Buttressing - by increasing juror confidence in a conclusion to which other, non-neuroscientific evidence already independently points (such as in the context of "diminished capacity" determinations);

2. Challenging - by calling into question or contradicting either other evidence in a case or a relevant legal assumption (such as those reflected in certain evidentiary rules);

3. Detecting - by identifying the existence of legally relevant facts (such as injuries, lies, or pain);

4. Sorting - by separating people into useful categories (such as those most likely to respond to drug rehabilitation);

5. Intervening - by providing new methods to achieve legal goals (such as through pharmacological interventions that would help to reduce recidivism);

6. Explaining - by illuminating decision pathways with information that may lead to more informed and less biased decisions (such as in the context of third-party punishment [TPP] decisions);

7. Predicting — by improving law's ability to estimate probabilities of future behavior (such as future violence). 


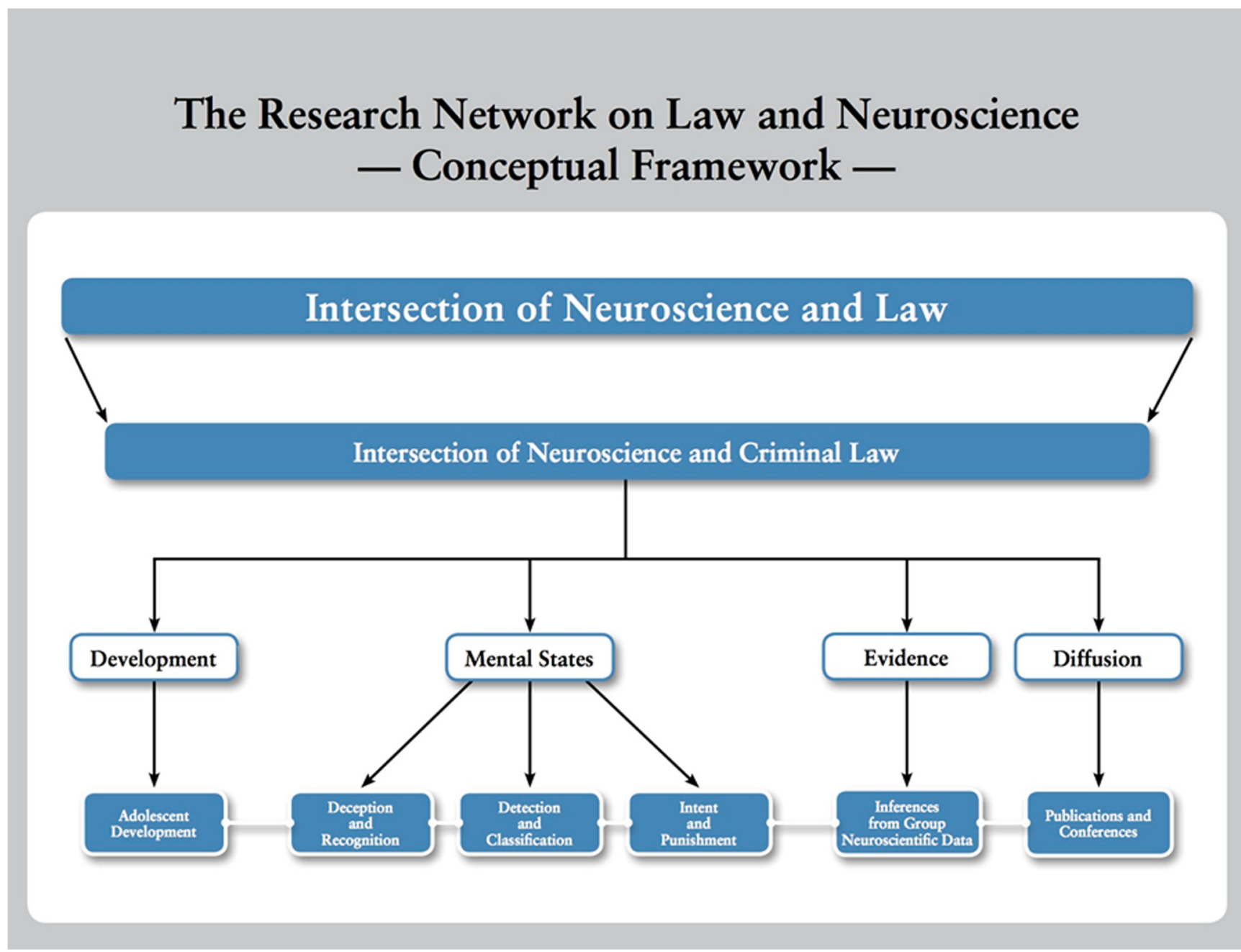

Figure 1. Conceptual framework of the MacArthur Foundation Research Network on Law and Neuroscience (www.lawneuro.org).

Some of these possible uses are speculative, more theoretical than current. Others reflect cases already arising in both criminal and civil contexts. For example, in the criminal case United States of America v. Lorne Allan Semrau, the defendant offered during the liability phase of his trial fMRI evidence that purportedly showed he did not actually intend to defraud the government. That evidence was ultimately excluded (because of particular weaknesses in the experimental protocol and a lack of the method's acceptance in the relevant scientific community) (Wagner, 2010; Shen and Jones, 2011; Greely and Wagner, 2011). And in Florida v. Grady Nelson, the defendant offered EEG evidence of brain function abnormalities in an effort to avoid being sentenced to death for the murder of which he'd been convicted. The court admitted the evidence, and the defendant was by a narrow margin sentenced instead to life in prison. Two jurors reported afterward that the brain evidence made the difference in their voting not to execute him (Miller, 2010). In civil cases, brain evidence appears increasingly in, for instance, lawsuits involving injuries to the head, including both tort actions and suits over disability benefits.

Although cases such as the foregoing tend to encounter neuroscientific evidence that is specific to individuals before the court, it is important to emphasize that the legal system sometimes encounters neuroscientific studies based on group data. For example, neuroscientific approaches to defining death by brain measures have been broadly influential. And in the recent case, Miller v Alabama, the United States Supreme Court referenced, in finding that mandatory sentences of life without the possibility of parole are unconstitutional for juvenile offenders, group-based brain science findings regarding impulse control, planning ahead, and risk avoidance.

There are numerous other neurolaw developments, outside of the litigation context, of which interested readers should be aware. For example, the MacArthur Foundation has invested over $\$ 15,000,000$ in creating the Law and Neuroscience Project (2007-11, headquartered at University of California, Santa Barbara) and the Research Network on Law and Neuroscience (2011-14, headquartered at Vanderbilt University) (www. lawneuro.org) (Fig. 1). The principal mission has been to create partnerships among neuroscientists, judges, and legal scholars to: (1) guide the legal system in finding the promise of neuroscientific insights among the perils of interpreting them; and (2) conduct new, collaborative, interdisciplinary research that may help to increase the fairness and effectiveness of the criminal justice system.

In parallel to these developments, there has been a sharp rise in both conceptual and empirical scholarship in neurolaw (Fig. 2), conferences, international neurolaw societies, "law and neuroscience" courses being taught in law and other departments internationally, and so on. The field has inspired new research and 


\section{Cumulative Total of Law and Neuroscience Publications: 1984-2013}

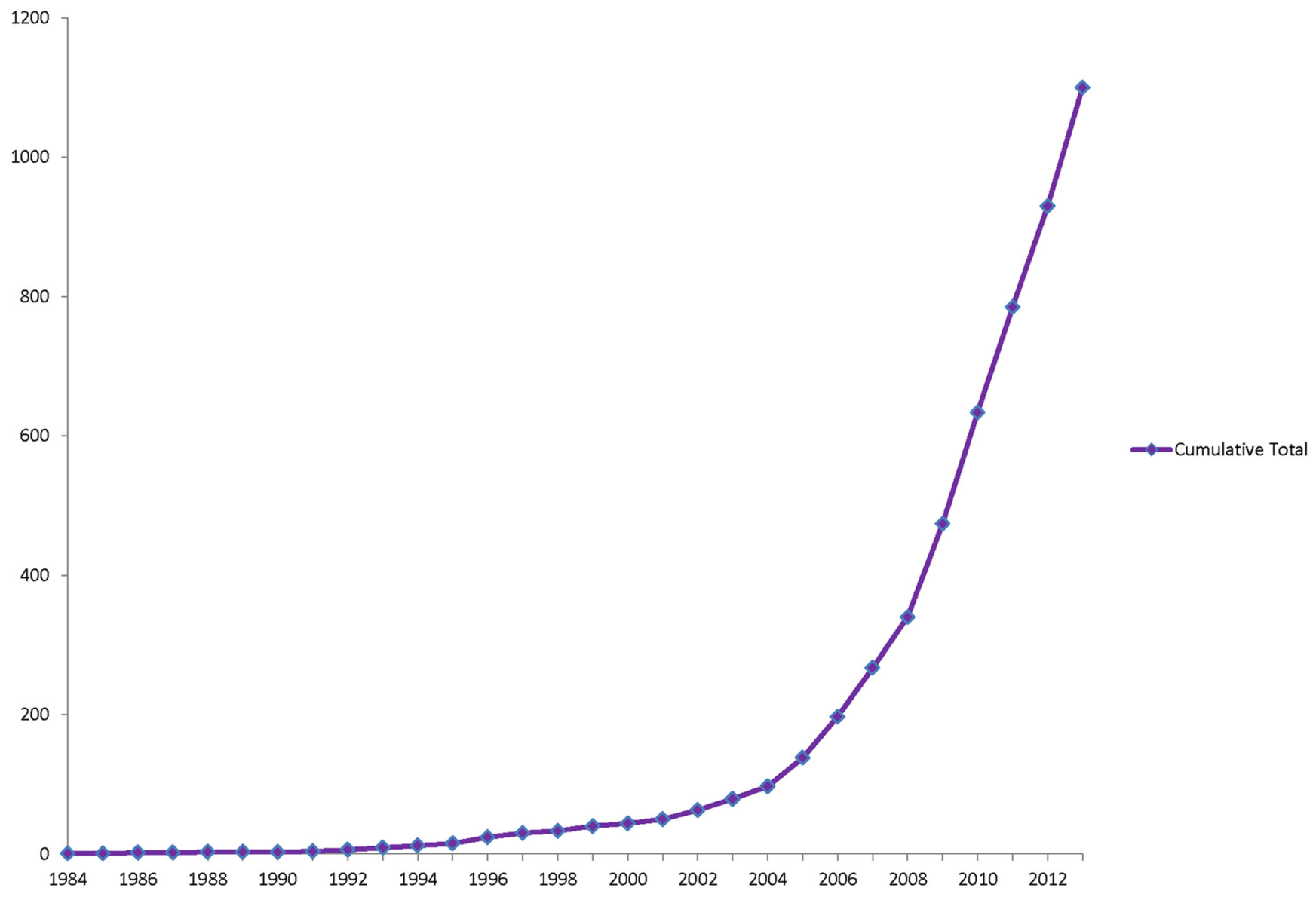

Figure 2. Cumulative total of publications in law and neuroscience. Data from Law and Neuroscience Bibliography, MacArthur Foundation Research Network on Law and Neuroscience (http://www.lawneuro.org/bibliography.php).

training programs (such as those at Law and Neuroscience at Vanderbilt University, Neuroscience and Public Policy at University of Wisconsin, Penn Neuroscience Boot Camp, and Initiative on Neuroscience and the Law), and will see its first dedicated coursebook in 2014 (Jones et al., 2013a). Moreover, there have been a plethora of judicial training seminars (sponsored by the Research Network on Law and Neuroscience, the American Association for the Advancement of Science, the Federal Judicial Center, the Gruter Institute, and others), as well as an increase in legal academics and professionals seeking short but immersive training in neuroscience (most prominently at the University of Pennsylvania Neuroscience Boot Camp).

These developments, and others like them, signal some of the many potential applications of neuroscientific insights in legal contexts, as the next three sections illustrate in more detail.

\section{The neural basis of legal decision-making}

Although much of the interest in neurolaw has focused on understanding the mind and brain of criminals, neuroscience can also make important contributions with respect to jurors and judges. For a fair and just legal system relies on the sound judgment of these impartial third parties, as they decide the culpability of defendants and assign appropriate punishments. Notwithstanding the often high stakes, legal decision-making is prone to the same influences and vagaries as are other decisionmaking processes. For example, the issue of race bias has plagued the justice system, from racial profiling to contested court decisions (as in the recent George Zimmerman case; Florida v. George Zimmerman). Given that even factors as benign as the timing of a parole decision relative to the decider's lunch break can dramatically influence outcomes (Danzinger et al., 2011), it seems clear that developing a broader and deeper understanding of the neural mechanisms of legal decisions might ultimately aid efforts to improve the fairness and effectiveness of the criminal justice system.

Fortunately, the initial foray of legal decision-making into the neuroscientific realm can benefit from decades of research on the neural bases of general decision-making, from single cells to systems (Gold and Shadlen, 2001; Schall, 2001), and from simple sensory decisions in monkeys to complex decision processes in humans (Lee, 2013). Even more pertinent is the work investigating the neural mechanisms underlying second-party punishment ('I punish you for harming me') (Sanfey et al., 2003; Knoch et al., 2006). And, to the extent that TPP refers to an aversive reaction to the violation of social norms, the emerging study of legal decision-making overlaps substantially with the field of moral neuroscience (Greene et al., 2001; Moll et al., 2005; Klieman et al., 2008), save for the pivotal role that punishment decisions play in the legal field.

Correspondingly, initial neuroimaging studies of TPP have used paradigms similar to those used in the moral field. This includes, for example, the presentation to subjects of scenarios 


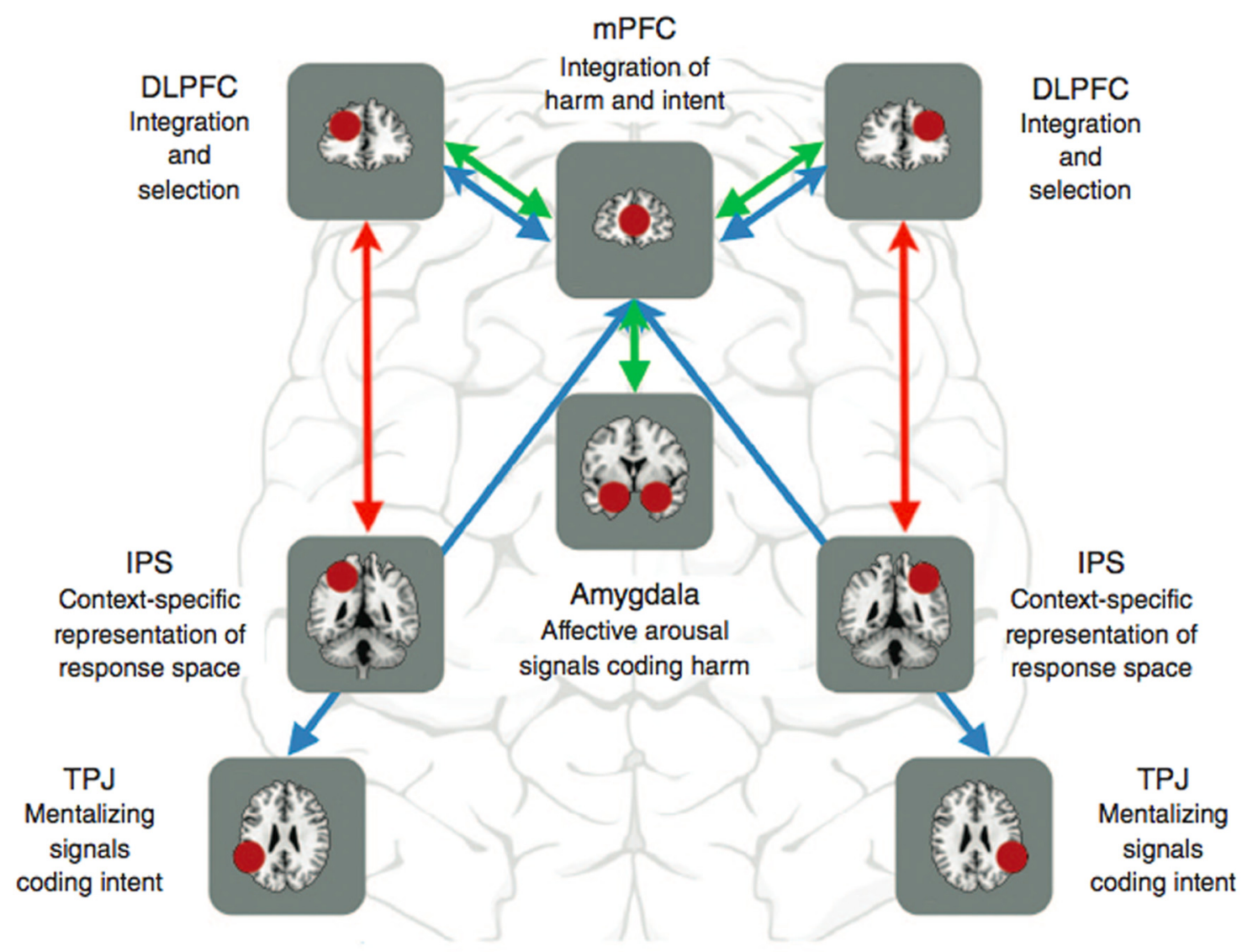

Figure 3. A neurocognitive hypothesis for third-party punishment behavior. (Buckholtz and Marois, 2012).

that depict the prohibited actions of a protagonist, following which the subjects are tasked to evaluate and assess the appropriate punishment for these actions (e.g., Buckholtz et al., 2008). By manipulating factors crucial to determining punishment, in particular, the severity of the harm caused by the act and the mental state that the protagonist was in when he committed this act, one can start parsing the brain mechanisms underlying TPP.

This approach initially highlighted a network of prefrontal, temporoparietal, and corticolimbic brain regions involved in TPP decisions (Buckholtz et al., 2008). It then led to the development of a neural network model of TPP, in which the temporoparietal cortex decodes the action(s) of the protagonist and infers his mental state, a corticolimbic circuit comprised of the amygdala and medial prefrontal cortex provides a neural heuristic for the amount of emotional arousal provoked by the harm, and the dorsolateral prefrontal cortex integrates this information to select an appropriate punishment outcome (Buckholtz and Marois, 2012) (Fig. 3).

More recent work has extended these findings and perspectives, providing support for the TPP model by demonstrating that transcranial magnetic stimulation to the dorsolateral prefrontal cortex disrupts punishment assignment while leaving blameworthiness evaluation intact (Buckholtz et al., manuscript in preparation), thereby providing neural evidence for a dissociation between the process of evaluating blame and assigning the appropriate punishment. And other, similar studies not only provide compelling evidence for the role of emotional arousal in punishment decisions, they also identify the brain mechanisms by which the mental state of the defendant can trump the harm caused by his actions because punishment may be waived alto- gether when such actions are caused accidentally and without negligence (Treadway et al., manuscript in preparation).

Notably, these findings generally align with studies of secondparty punishment during simple neuro-economic games (Sanfey et al., 2003; Knoch et al., 2006). That suggests that the mechanisms by which judges arrive at a punishment decision from an uninvolved and unbiased perspective are very much the same as those engaged when we decide to punish those who have done us wrong directly. Similarly, mounting evidence for the critical role of the corticolimbic circuit in punishment decision-making highlights the pivotal functions that emotions serve in this cognitive process. This provides some potentially telling neurobiological counterpoint to the frequent lay assumption that TPP decisions can be made, and frequently are made, with reason unclouded by emotion. And these methods provide a framework to study bias (for example, with the introduction of prior evidence about the character of a defendant), with an eventual goal of reducing the presence of such biases in legal decision-making.

To be sure, this neurobiological research is typically performed under conditions that are remote from the court environment, as well as with participants who have no specific legal expertise. However, recent work suggests that methods such as these yield findings that appear to apply also in more legalistic contexts (Schleim et al., 2011). Consequently, this line of research illustrates the kinds of contributions that neuroscience can make to our understanding of how liability and punishment decisions are made.

\section{Ethics in neurolaw}

Neuroscience intersects with the law in multiple ways, and the ethical impact of neuroscience is similarly diverse (Morse, 2006; 
Farah, 2012). To facilitate thinking clearly about the numerous ethical issues that arise in neurolaw, two general distinctions are useful.

The first broad distinction concerns the role of neuroscience in decisions about criminal responsibility. To be found guilty in the U.S. legal system, a defendant must not only have performed a prohibited act, she must also have done so in a legally culpable state of mind. For example, if Mary suffers an unexpected seizure while standing on a subway platform and bumps into John, causing him to tumble to his death beneath the wheels of an oncoming train, Mary is not guilty of murder. Yet if she purposefully gave the same bump to John, intending his death by subway car, she would be. Neuroscience has sometimes been taken to suggest that the two scenarios are fundamentally the same and that therefore the legal outcomes should also be the same.

Here is the reasoning: the motives that led Mary to push John purposefully onto the train tracks are products of her brain, which was in turn shaped by her genes and her environment, neither of which she chose. Accordingly, she is no more "responsible" for her act when she intends it than she is when she has an uncontrollable seizure.

Of course, no defense attorney has ever faced a jury and argued "Because of processes set in motion at the time of the Big Bang, my client could not have acted otherwise, and consequently must be innocent." We should therefore distinguish this role for neuroscience in law, casting doubt on the very possibility of responsibility, from the way in which neuroscience is actually applied to the determination of responsibility.

Law generally assumes that people are responsible for their actions. It nonetheless allows some exceptions, through application of commonsensical psychological criteria. These include, for example, assessments of a defendant's intentions, understanding, rationality, and self-control at the time of the prohibited act. Within this framework, neuroscientific evidence is essentially one more source of evidence regarding these psychological traits and states. Here are two examples within this responsibility domain.

One concerns the role of neuroscience in enabling legal decisions about entire groups of people. The U.S. Supreme Court has recently invoked group-based neuroscientific evidence concerning the immaturity of the adolescent brain to help reach groupwide conclusions about the extent of adolescent liability for criminal behavior. The neuroscience is relevant because it provides additional support for understanding immature judgment and self-control.

The other example concerns the ability of neuroscience to provide evidence specific to individual defendant. In New York v. Herbert Weinstein, a man with no history of mental disorder killed his wife in a violent rage. Subsequent neuroimaging revealed a large arachnoid cyst compressing his prefrontal cortex. The defense offered the scan as evidence that he had impaired self-control, and this reportedly drove a favorable plea bargain. Here, the neuroscience provided information intended to augment the legal system's understanding of the man's psychological capacities, and hence his own, individualized responsibility.

A second broad distinction, regarding the ethics of neurolaw, concerns the role of neuroscience generating ethical issues. In some cases, ethical challenges arise for reasons not directly related to neuroscience per se. For example, the ethics of predicting recidivism with neuroimaging depends on factors such as the method's accuracy and the consequences of false positives and negatives. The fact that the prediction is based on information about the brain is largely irrelevant from an ethical standpoint. In cases such as these, precedents from non-neuroscientific analyses (such as from other types of predictive testing) can help us to anticipate ethical problems and to seek solutions.

Other legal applications of neuroscience, in contrast, can raise novel ethical issues. For example, suppose that a convicted man were sentenced to a brain intervention instead a behavioral intervention, such as anger management therapy. That would raise ethical issues not encountered with traditional methods of behavior change. With behavioral interventions, the offender must typically choose to use the skills he learned. With brain interventions such as medication, however, the changes bypass the offender's decisionmaking, arguably infringing on his autonomy at a very different level.

These two broad roles of neuroscience in law-to deepen psychological knowledge (as in the case of criminal responsibility) and to generate new but potentially controversial tools (as in the cases of predicting recidivism or enabling direct brain interventions) - raise important ethical issues with which society and the legal system will be grappling for some time.

\section{Beyond criminal responsibility: other issues in law and neuroscience}

Most of the scholarly discussion about law and neuroscience has revolved around questions of responsibility. If neuroscience can help us connect physical states of the brain with subjective mental states, that should indeed prove useful. However, neuroscience seems poised to offer law much more. For example, neuroscience should improve our predictions of future mental states and consequent behavior, it may help us learn about relevant current states of mind, it might allow us to intervene more directly in the brain to treat nondisease behaviors, and it could lead to the development of new ways to enhance human mental capabilities. The law, both directly and indirectly, will be involved in all of these developments (Greely, 2009).

By providing us with better understandings of the physical roots of neurological diseases, mental illnesses, and nonpathological behaviors, neuroscience may improve our predictions of a person's future. In some cases, this might be better understood as early diagnosis of a disease process, before it shows clear (or any) symptoms. An example is detection of early effects of Alzheimer disease, through PET scans for amyloid plaque build-up or from biomarkers in cerebral spinal fluid. In other cases, such as the correlation between certain genetic variants and future Alzheimer disease, it may be more purely prediction. In either case, however, our improved understanding of conditions such as Alzheimer disease, schizophrenia, Parkinson's disease, and others, could improve our ability to predict who will and will not be diagnosed with the illness. This has clear implications for the legal system through the legal issues that will arise around employment, insurance, education, and other benefits that might be denied, or provided, based on such predictions. (One could also imagine, for example, possible judicial appointees being asked for medical evidence of their risks for Alzheimer disease.) As the same understanding improves early diagnosis, it may well have an even more direct effect on legal proceedings, influencing decisions about a person's competency to be a witness or to control his own funds and important life decisions.

Neuroscience-based predictions might also change the legal system more directly, by improving our ability to predict someone's future violent or criminal behavior. The legal system already uses such predictions in making decisions regarding bail, sentencing, parole, the death penalty, and even, in some psychiatric and sexual offender contexts, preventive detention. Some- 
times the predictions are subjective. Other times they are clinical. In still others evidence from social science has been used to create predictive algorithms. Neuroscience, perhaps through neuroimaging of a defendant, may either on its own, or in combination with existing methods, be able to improve the accuracy of these predictions (Aharoni et al., 2012).

Neuroscience may also help us ascertain someone's current mental state. That could be extremely valuable, for example, in trying to decide whether a plaintiff actually is experiencing the disabling pain he claims. Legal systems make millions of these decisions every year, often with little evidence other than the claimant's self-report. Neuroimaging results that correlate strongly with the presence or absence of subjective pain may never be perfect. But they may be much better than our current tools (Kolber, 2007). Similarly, neuroscience might help detect whether a person recognizes something (Meixner and Rosenfeld, 2011) has a particular emotional response to something, or even, possibly, whether that person is trying to deceive. Any of these forms of "mind-reading" could be extremely useful in court, and sometimes outside of it. And they will raise, in the United States at least, complicated constitutional issues involving the Fourth (Farahany, 2012b) and Fifth (Farahany, 2012a) Amendments.

Looking at neuroscientific research in broad context, it's clear that the greatest interest in and funding for neuroscience research is not driven by enthusiasm for applications in prediction or detection. It is instead being driven by hoped-for interventions. We want treatments that prevent, mitigate, or cure diseases of the brain. Although useful interventions from neuroscience have been uncommon so far, it is the hope of them that funds this research. The key point for law, however, is that, if we succeed in treating some kinds of disease, the depth of understanding that requires may also allow the "treatment" of mental states that are not diseases. Shyness, sexual orientation, religiosity (or its absence), and political preferences are all traits that some people may want to change, either in themselves or in others. Whether direct brain interventions were to be imposed by judges seeking to "rehabilitate" criminals; by parents seeking to "improve" their children; or by competent adults seeking to "change their selves," the legal and regulatory system will necessarily be involved. (Greely, 2008).

Finally, neuroscience may lead to new methods for enhancing mental abilities. Controversy has stalked the nonmedical use of Adderall or Ritalin for their (very unclear) cognitive enhancing powers. But what if medical research on disease treatments leads to the creation of drugs or devices with proven effectiveness at enhancing the healthy? How would we want such enhancements to be used, in society in general and even in the legal system? (Think of enhancing witnesses' memories or helping students pass the bar examination) (Greely et al., 2008).

In all of these applications of neuroscience, and more, the law will necessarily be involved. In some, it will be called upon to set, interpret, and enforce the limits of actions made possible by neuroscience. In others, neuroscience will affect the law's own processes, from the courtroom to the corporate lawyer's office to issues of judicial appointment. One way or the other, law and neuroscience will be increasingly bound together on questions that go far beyond responsibility.

\section{Conclusions}

As discussed above, there are a wide variety of contexts in which neuroscience might aid the legal system substantially. We believe there are ample reasons for optimism. But, in light of many attendant challenges, we of course counsel caution as well. There are inherent limitations in the current states of neuroscientific knowledge. And there are difficult, although not insurmountable, challenges in communicating across the law/neuroscience disciplinary divide, as well as in carefully and properly interpreting neuroscientific evidence within the specific legal contexts in which it is offered (Jones et al., 2013b). Not surprisingly, the intersections of law and neuroscience have prompted some debate over whether we will in fact see, at the frontier edges of this new discipline, a net gain in the fair and effective administration of justice, and in what specific contexts (Greene and Cohen, 2004; Sapolsky, 2004; Morse, 2006, 2010, 2011; Patel et al., 2007; Pustilnik, 2009; Brown and Murphy, 2010; Hughes, 2010; Mayberg, 2010; Morse, 2010, 2011; Pardo and Patterson, 2010; Legrenzi et al., 2011; Satel and Lilienfeld, 2013). But in our view, one thing is utterly clear. The extent to which the legal system can avail itself of the best neuroscience has to offer, and can also best avoid misrepresentations or misinterpretations of neuroscientific evidence, will depend in part on the extent and quality of the engagement of neuroscientists with the myriad researchable issues that already exist within the arena (Jones et al., 2013b), as well as with the many new issues that will inevitably arise, only some of which can currently be foreseen.

\section{References}

Aharoni E, Vincent GM, Harenski CL, Calhoun VD, Sinnott-Armstrong W, Gazzaniga MS, Kiehl KA (2012) Neuroprediction of future rearrest. Proc Natl Acad Sci U S A 110:6223-6228. CrossRef Medline

American Association for the Advancement of Science. http://www.aaas.org/

Brown T, Murphy E (2010) Through a scanner darkly: functional neuroimaging as evidence of a criminal defendant's past mental states. Stanford L Rev 62:1119-1208.

Buckholtz JW, Marois R (2012) The roots of modern justice: cognitive and neural foundations of social norms and their enforcement. Nat Neurosci 15:655-661. CrossRef Medline

Buckholtz JW, Asplund CL, Dux PE, Zald DH, Gore JC, Jones OD, Marois R (2008) The neural correlates of third-party punishment. Neuron 60: 930-940. http://papers.ssrn.com/sol3/papers.cfm?abstract_id=1715509 CrossRef Medline

Center for Neuroscience and Society, University of Pennsylvania. http:// neuroethics.upenn.edu/

Danziger S, Levav J, Avnaim-Pesso L (2011) Extraneous factors in judicial decisions. Proc Natl Acad Sci U S A 108:6889-6892. CrossRef Medline

Davis K (2012) Brain trials: neuroscience is taking a stand in the courtroom. ABA J 98:36-37.

Farah MJ (2012) Neuroethics: the ethical, legal and societal impact of neuroscience. Annu Rev Psychol 63:571-591. CrossRef Medline

Farahany N (2012a) Incriminating thoughts. Stanford L Rev 64:351-408.

Farahany N (2012b) Searching secrets. Penn L Rev 160:1239-1308.

Florida v. George Zimmerman. No. 12-CF-1083-A (18th Fla. Cir. Ct., 13 July 2013).

Florida v. Grady Nelson. No. F05-00846 (11th Fla. Cir. Ct., 4 Dec 2010).

Freeman M, Goodenough OR, eds (2009) Law, mind, and brain. Farnham, UK: Ashgate.

Garland B (2004) Neuroscience and the law: brain, mind, and the scales of justice. Washington, D.C.: Dana.

Gazzaniga MS (2008) The law and neuroscience. Neuron 60:412-415. CrossRef Medline

Gold JI, Shadlen MN (2001) Neural computations that underlie decisions about sensory stimuli. Trends Cogn Sci 5:10-16. CrossRef Medline

Greely HT (2008) Neuroscience and criminal justice: not responsibility but treatment. Univ Kans L Rev 56:1103-1138.

Greely HT (2009) Law and the revolution in neuroscience: an early look at the field. Akron L Rev 42:687-715.

Greely HT, Wagner AD (2011) Neuroscience, reference guide on neuroscience, reference manual on scientific evidence, pp 747-812. Washington, D.C. Federal Judicial Center and National Academies.

Greely H, Sahakian B, Harris J, Kessler RC, Gazzaniga M, Campbell P, Farah MJ (2008) Towards responsible use of cognitive-enhancing drugs by the healthy. Nature 456:702-705. CrossRef Medline 
Greene J, Cohen J (2004) For the law, neuroscience changes nothing and everything. Philos Trans R Soc Lond B Biol Sci 359:1775-1785. CrossRef Medline

Greene JD, Sommerville RB, Nystrom LE, Darley JM, Cohen JD (2001) An fMRI investigation of emotional engagement in moral judgment. Science 293:2105-2108. CrossRef Medline

Gruter Institute for Law and Behavioral Research. http://www.gruterinstitute. org/Home.html

Hughes V (2010) Science in court: head case. Nature 464:340-342. CrossRef Medline

Initiative on Neuroscience and the Law, Baylor College of Medicine. http://www.neulaw.org/

Jones OD (2013) Seven ways neuroscience aids law. In: Neurosciences and the human person: new perspectives on human activities (Battro A, Dehaene S, Singer W, eds), Scripta Varia 121. Vatican City: Pontifical Academy of Sciences. http://papers.ssrn.com/sol3/papers.cfm?abstract_ id $=2280500$

Jones OD, Shen FX (2012) Law and neuroscience in the United States: international neurolaw (Spranger T, ed). New York: Springer. http:// papers.ssrn.com/sol3/papers.cfm?abstract_id $=2001085$

Jones OD, Schall JD, Shen FX (2013a) Law and neuroscience. In press. New York: Aspen.

Jones OD, Wagner AD, Faigman DL, Raichle ME (2013b) Neuroscientists in court. Nat Rev Neurosci 14:730-736. CrossRef Medline

Kliemann D, Young L, Scholz J, Saxe R (2008) The influence of prior record on moral judgment. Neuropsychologia 46:2949-2957. CrossRef Medline

Knoch D, Pascual-Leone A, Meyer K, Treyer V, Fehr E (2006) Diminishing reciprocal fairness by disrupting the right prefrontal cortex. Science 314: 829-832. CrossRef Medline

Kolber AJ (2007) Pain detection and the privacy of subjective experience. Am J L Med 33:433-456.

Law and Neuroscience at Vanderbilt University. http://www.vanderbilt. edu/neurolaw/

Lee D (2013) Decision making: from neuroscience to psychiatry. Neuron 78:233-248. CrossRef Medline

Legrenzi P, Umilta C, Anderson F (2011) Neuromania: on the limits of brain science. Oxford: Oxford UP.

MacArthur Foundation Research Network on Law and Neuroscience. Bibliography of law and neuroscience. http://www.lawneuro.org/bibliography. php

Mackintosh N (2011) Brain waves 4: neuroscience and the law. London, UK: Royal Society.

Mayberg HS (2010) Does neuroscience give us new insights into criminal responsibility? In: A judge's guide to neuroscience, pp 37-41. Santa Barbara, CA: SAGE Center for the Study of the Mind.

Meixner JB, Rosenfeld JP (2011) A mock terrorism application of the P300-based concealed information test. Psychophysiology 48:149154. CrossRef

Miller G (2010) Brain exam may have swayed jury in sentencing convicted murderer. Science (14 Dec 2010). http://news.sciencemag.org/technology/ 2010/12/brain-exam-may-have-swayed-jury-sentencing-convicted-murderer
Miller v. Alabama, 567 U.S. (forthcoming 2012).

Moll J, Zahn R, de Oliveira-Souza R, Krueger F, Grafman J (2005) Opinion: the neural basis of human moral cognition. Nat Rev Neurosci 6:799-809. CrossRef Medline

Morse SJ (2006) Brain overclaim syndrome and criminal responsibility: a diagnostic note. Ohio St J Crim L 3:397-412. http://papers.ssrn.com/ sol3/papers.cfm?abstract_id $=896753$

Morse SJ (2010) Lost in translation? An essay on law and neuroscience. In: Law and neuroscience: current legal issues (Freeman M, ed). Oxford: Oxford P. http://papers.ssrn.com/sol3/papers.cfm?abstract_id=1904488

Morse SJ (2011) Avoiding irrational neurolaw exuberance: a plea for neuromodesty. Mercer L Rev 62:837-859.

Morse SJ, Roskies AL, eds. (2013) A primer on criminal law and neuroscience. Oxford: Oxford P.

Neuroscience and Public Policy at University of Wisconsin, Madison. http://npp.wisc.edu/

New York v. Herbert Weinstein. No. 156 Misc.2d 34 (591 N.Y.S.2d 715, 1992).

Pardo MS, Patterson D (2010) Philosophical foundations of law and neuroscience. Ill L Rev 2010:1211-1250.

Patel P, Meltzer CC, Mayberg HS, Levine K (2007) The role of imaging in United States courtrooms. Neuroimaging Clin North Am 17:557-567. CrossRef Medline

Penn Neuroscience Boot Camp, University of Pennsylvania. http:// neuroethics.upenn.edu/index.php/events/neuroscience-bootcamp

Pustilnik AC (2009) Violence on the brain: a critique of neuroscience in criminal law. Wake Forest L Rev 44:183-237.

Sanfey AG, Rilling JK, Aronson JA, Nystrom LE, Cohen JD (2003) The neural basis of economic decision-making in the ultimatum game. Science 300:1755-1758. CrossRef Medline

Sapolsky RM (2004) The frontal cortex and the criminal justice system. Philos Trans R Soc Lond B Biol Sci 359:1787-1796. CrossRef Medline

Satel S, Lilienfeld SO (2013) Brainwashed: the seductive appeal of mindless neuroscience. New York: Basic.

Schall JD (2001) Neural basis of deciding, choosing and acting. Nat Rev Neurosci 2:33-42. CrossRef Medline

Schleim S, Spranger TM, Erk S, Walter H (2011) From moral to legal judgment: the influence of normative context in lawyers and other academics. Soc Cogn Affect Neurosci 6:48-57. CrossRef Medline

Shen FX, Jones OD (2011) Brain scans as evidence: truth, proofs, lies, and lessons. Mercer L Rev 62:861-883. http://papers.ssrn.com/sol3/papers. cfm?abstract_id $=1736288$

Spranger T, ed (2011) International neurolaw. New York: Springer.

United States of America v. Lorne Allan Semrau. 07-10074 (2010) Opinion by Judge Pham (June 1, 2010: http://www.tnwd.uscourts.gov/JudgePham/ opinions/659.pdf

Wagner A (2010) Can neuroscience identify lies? In: A judge's guide to neuroscience: a concise introduction. Santa Barbara, CA: SAGE Center for the Study of the Mind.

Zeki S, Goodenough OR, eds (2006) Law and the brain. Oxford, UK: Oxford UP. 